T. Drivsholm $\cdot$ N. de Fine Olivarius $\cdot$ A. B. S. Nielsen •

V. Siersma

\title{
Symptoms, signs and complications in newly diagnosed type 2 diabetic patients, and their relationship to glycaemia, blood pressure and weight
}

Received: 19 April 2004 / Accepted: 22 October 2004 / Published online: 14 January 2005

(C) Springer-Verlag 2005

\begin{abstract}
Aims/hypothesis: To document the prevalence of typical diabetic symptoms, signs and complications in the diagnosis of type 2 diabetes mellitus, examine their prediagnostic duration, and analyse associations with glycaemic level, blood pressure (BP), and weight. Methods: An epidemiological population-based study of 1137 Danish patients with type 2 diabetes newly diagnosed by general practitioners (GPs). GPs and patients together filled in a questionnaire about typical symptoms, signs and complications preceding the diagnosis. Results: Abnormal thirst, frequent urination, weight loss, genital itching, stomatitis, visual disturbances, fatigue, confusion and (in men) balanitis were associated with glycaemic level irrespective of age, sex, BMI, BP, complications and antihypertensive treatment. Eighty-nine percent of the patients presented with one or more of these hyperglycaemic symptoms and signs, and the pre-diagnostic duration was typically less than 3 months. Only a few symptoms, signs and complications were associated with weight and BP. Conclusions/interpretation: In patients newly diagnosed with type 2 diabetes in family practice, typical diabetic symptoms, signs and complications are common. Typical diabetic symptoms and signs are associated with hyperglycaemia. The pre-diagnostic duration of hyperglycaemic symptoms and signs were typically short, thus questioning the feasibility of early detection relying on increased anticipatory care by GPs. In contrast, elevated levels of cardiovascular risk factors and longer pre-diagnostic duration of cardiovascular complica-
\end{abstract}

T. Drivsholm $(\bowtie) \cdot$ N. de Fine Olivarius · A. B. S. Nielsen ·

V. Siersma

Research Unit of General Practice, Copenhagen,

Kommunehospitalet, Center for Sundhed og Samfund,

5 Øster Farimagsgade,

2099, 1014 Copenhagen K, Denmark

e-mail: thomas.drivsholm@gpract.ku.dk

Tel.: +45-3532-7171

Fax: $+45-3532-7131$

V. Siersma

Department of Biostatistics, Institute of Public Health,

University of Copenhagen,

Copenhagen, Denmark tions suggest these might have a central role in an early diagnosis of type 2 diabetes.

Keywords Complication - Epidemiology $\cdot$ Family practice Prevalence $\cdot$ Type 2 diabetes mellitus $\cdot$ Signs and symptoms

Abbreviations FPG: Fasting plasma glucose - GP: General practitioner - IQR: Interquartile range - UKPDS: United Kingdom Prospective Diabetes Study

\section{Introduction}

The long-term aim in the treatment of type 2 diabetic patients is prevention of complications. Efforts to ameliorate immediate symptoms and signs of diabetes might, however, improve patients' quality of life in the short term and increase their motivation for lifestyle changes and medication. Despite the central role of symptoms and signs in the treatment of type 2 diabetes, few studies have studied the prevalence and duration of symptoms and signs at diabetes diagnosis [1-7]. Associations between typical diabetic symptoms and glycaemic level, blood pressure (BP), and weight are, furthermore, ambiguous and documented for a few symptoms only $[1,2]$. Clearer insight into these associations might help discover which symptoms and signs have a potential for improving screening activity and treatment quality in newly diagnosed type 2 diabetic patients.

We report the prevalence and pre-diagnostic duration of diabetic symptoms, signs and complications, and their association with glycaemia, BP and weight, in a populationbased sample of 1,137 patients with newly diagnosed type 2 diabetes.

\section{Subjects and methods}

A total of 474 general practitioners (GPs) volunteered for the study Diabetes Care in General Practice, a randomised controlled trial of structured diabetes care [8]. From March 
Table 1 Baseline characteristics of 1,137 patients with newly diagnosed type 2 diabetes mellitus according to gender
Data are means (SD), medians (IQR), or prevalence proportions in percent

${ }^{\text {a }}$ Statistical test: $t$-test

b Statistical test: Wilcoxon test

${ }^{\mathrm{c}} \mathrm{HbA}_{1} \mathrm{c}$ measured 0-45 days after diagnosis $(n=1,003)$, median 7 days (interquartile range 3-15), reference interval 5.4$7.4 \%$

d Statistical test: chi square test

\begin{tabular}{|c|c|c|c|}
\hline \multicolumn{4}{|l|}{ Clinical characteristics } \\
\hline Age (years) & $66.3(11.5)$ & $63.2(11.3)$ & $<0.001^{\mathrm{a}}$ \\
\hline Fasting plasma glucose $(\mathrm{mmoL} / \mathrm{L})$ & $13.7(10.5-17.0)$ & $13.9(11.0-17.0)$ & $0.50^{\mathrm{b}}$ \\
\hline $\mathrm{HbA}_{1} \mathrm{c}(\text { fraction, } \%)^{\mathrm{c}}$ & $10.2(8.7-11.9)$ & $10.3(8.8-11.9)$ & $0.52^{\mathrm{b}}$ \\
\hline BMI $\left(\mathrm{kg} / \mathrm{m}^{-2}\right)$ & $30.4(5.9)$ & $29.4(4.7)$ & $0.002^{\mathrm{a}}$ \\
\hline Systolic blood pressure (mmHg) & $153.9(22.6)$ & $145.5(21.2)$ & $<0.001^{\mathrm{a}}$ \\
\hline Diastolic blood pressure $(\mathrm{mmHg})$ & $85.1(10.8)$ & $85.5(10.8)$ & $0.58^{\mathrm{a}}$ \\
\hline \multicolumn{4}{|l|}{ Smoking status: $(\%)$} \\
\hline Never smoked & 50 & 14 & $<0.001^{\mathrm{d}}$ \\
\hline Previous smoker & 24 & 44 & \\
\hline Current smoker & 26 & 42 & \\
\hline Antihypertensive treatment (\%) & 55 & 38 & $<0.001^{\mathrm{d}}$ \\
\hline \multicolumn{4}{|l|}{ Complications } \\
\hline Macrovascular complications (\%) & 27.9 & 28.4 & $0.85^{\mathrm{d}}$ \\
\hline Prior or present myocardial infarction (\%) & 3.7 & 8.8 & $<0.001^{\mathrm{d}}$ \\
\hline Prior or present stroke $(\%)$ & 2.4 & 3.4 & $0.30^{\mathrm{d}}$ \\
\hline Angina pectoris $(\%)$ & 10.6 & 9.3 & $0.45^{\mathrm{d}}$ \\
\hline Intermittent claudication (\%) & 3.5 & 4.0 & $0.67^{\mathrm{d}}$ \\
\hline Amputation (\%) & 0.2 & 0.7 & - \\
\hline Missing pulses in feet (\%) & 14.0 & 12.1 & $0.34^{\mathrm{d}}$ \\
\hline Microvascular complications (\%) & 51.1 & 63.6 & $<0.0001^{\mathrm{d}}$ \\
\hline Retinopathy (\%) & 4.0 & 5.4 & $0.30^{\mathrm{d}}$ \\
\hline Renal involvement (\%) & 37.4 & 48.1 & $<0.001^{\mathrm{d}}$ \\
\hline Peripheral neuropathy (\%) & 19.1 & 19.1 & $1.00^{\mathrm{d}}$ \\
\hline At least one macro- or micro vascular complication (\%) & 64.2 & 71.1 & $0.02^{\mathrm{d}}$ \\
\hline
\end{tabular}

1989 to February 1992 the GPs included all patients aged $\geq 40$ years with newly diagnosed diabetes $(n=1,543)$. Diagnosis of diabetes reflected normal diagnostic procedures in Danish general practice, i.e. diagnosis was based on raised blood glucose values and/or typical diabetic symptoms, and was subsequently confirmed by a single fasting whole-blood (plasma) glucose sample $\geq 7.0(8.0) \mathrm{mmoL} / \mathrm{L}$
[8]. The protocol-based exclusion criteria were: life threatening somatic disease $(n=50)$, severe mental illness $(n=50)$, or unwillingness to participate $(n=62)$. Furthermore, 47 patients were excluded from the analyses because of treatment with steroids at diagnosis. Of the remaining 1,334 patients, $14.8 \%(n=197)$ were excluded because they were diagnosed outside general practice, their data consequently
Table 2 Prevalence and pre-diagnostic duration of symptoms, signs, and complications in 1,137 patients with newly diagnosed type 2 diabetes mellitus

The interview was median 8 days (interquartile range 3-19) after diagnosis.

${ }^{\text {a }}$ Cramp in calves, pain or paraesthesia in lower extremities

${ }^{b}$ Total prevalence of other reported symptoms: nausea, skin itching, headache, cramp in calves/pain or paraesthesia in upper extremities, sweating, pain in the eyes, haematuria, pharyngitis, hoarseness, itching eyes, stomach ache, lower back pain, vertigo, rigid joints, diarrhoea, cardiac insufficiency, paraesthesia in the face, constipation, mouth dryness, recurrent non-specific vaginitis, impotence, accentuated paradentosis, eczema and tinnitus

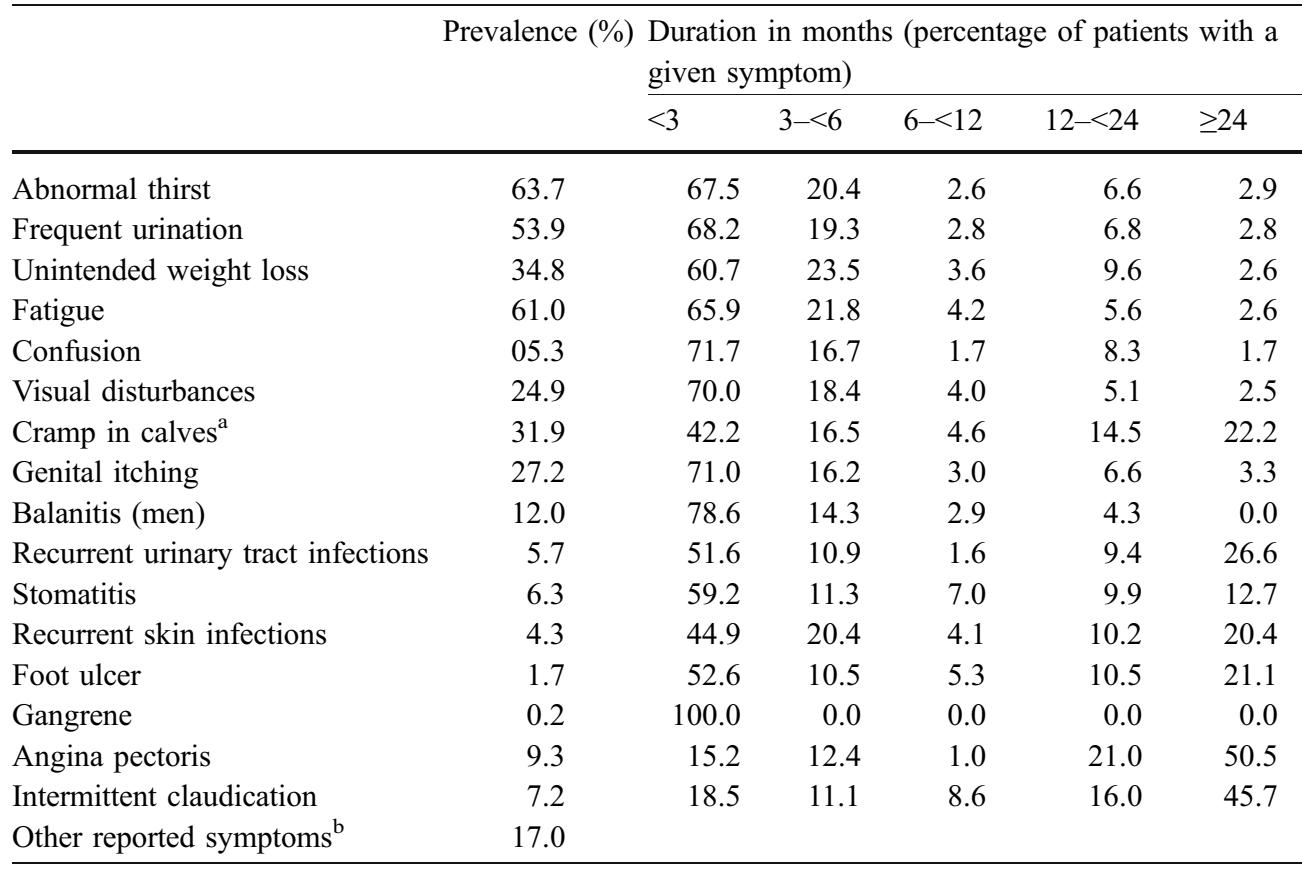


being collected with delay after diabetes diagnosis; this left 1,137 patients for the analyses.

At the time of diagnosis the GPs, with the patients, completed a questionnaire about the presence and approximate duration (number of weeks) of 16 typical diabetic symptoms, signs and complications (Table 2) selected on the basis of a literature search and interviews with experienced diabetologists. In addition, patients were asked if they had any other symptoms. The GPs also stated the reason(s) that initially led to glucose measurement, partly in four closed-ended questions (presence of symptoms or acute disease, high age, overweight, and prior sub-threshold elevation of blood glucose) and partly in an open-ended question allowing additional reasons to be stated.

Samples for diagnostic plasma or whole-blood glucose tests were drawn after a minimum of $8 \mathrm{~h}$ fasting and analysed at local laboratories $(n=72)$. A factor of 1.15 was used to convert whole-blood measurements $(n=678)$ to plasma glucose (FPG). Measurements of $\mathrm{HbA}_{1} \mathrm{c}$ were centralised. Other methods used have previously been reported in detail [8].

Informed consent was obtained from all study participants. The protocol was in accordance with the Helsinki declaration and was approved by the Ethics Committee of Copenhagen and Frederiksberg.

Univariate analyses were performed by routine statistical methods. The association between each risk factor, i.e. $\mathrm{FPG}, \mathrm{HbA}_{1} \mathrm{c}, \mathrm{BMI}$, and systolic $\mathrm{BP}$, and each of the 16 symptoms, signs, or complications was analysed by a logistic regression model using the individual symptom as dependent variable (present/not present) and risk factors as independent variables. Adjustment for macrovascular dis-

Table 3 Associations between single symptoms/signs/complications and glycaemia, blood pressure, and body mass index in patients with newly diagnosed type 2 diabetes

\begin{tabular}{|c|c|c|c|c|c|c|c|}
\hline \multirow[t]{2}{*}{ Independent variable } & \multirow[t]{2}{*}{ Dependent variable } & OR & $95 \% \mathrm{CI}$ & OR & $95 \% \mathrm{CI}$ & OR & $95 \% \mathrm{CI}$ \\
\hline & & \multicolumn{2}{|c|}{ Unadjusted } & \multicolumn{2}{|c|}{ Adjusted for 1,2} & \multicolumn{2}{|c|}{ Adjusted for $1,2,4-10$} \\
\hline \multirow[t]{10}{*}{$\mathrm{FPG}^{\mathrm{a}}(\mathrm{mmoL} / \mathrm{L})$} & Abnormal thirst & 1.17 & $1.14-1.21$ & 1.17 & $1.13-1.21$ & 1.17 & $1.12-1.21$ \\
\hline & Frequent urination & 1.12 & $1.09-1.16$ & 1.12 & $1.09-1.16$ & 1.13 & $1.09-1.16$ \\
\hline & Weight loss & 1.10 & $1.07-1.13$ & 1.10 & $1.07-1.13$ & 1.10 & $1.06-1.13$ \\
\hline & Fatigue & 1.04 & $1.01-1.06$ & 1.04 & $1.01-1.07$ & 1.04 & $1.01-1.07$ \\
\hline & Confusion & 1.05 & $1.02-1.09$ & 1.05 & $1.02-1.09$ & 1.06 & $1.03-1.10$ \\
\hline & Visual disturbances & 1.02 & $1.00-1.05$ & 1.03 & $1.00-1.05$ & 1.03 & $1.00-1.05$ \\
\hline & Genital itching & 1.02 & $1.00-1.05$ & 1.03 & $1.00-1.06$ & 1.03 & $1.00-1.06$ \\
\hline & Urinary tract infection $^{\mathrm{b}}$ & 0.95 & $0.90-1.01$ & 0.95 & $0.90-1.01$ & 0.95 & $0.89-1.01$ \\
\hline & Stomatitis & 1.03 & $1.00-1.06$ & 1.03 & $1.00-1.07$ & 1.04 & $1.00-1.08$ \\
\hline & & \multicolumn{2}{|c|}{ Unadjusted } & \multicolumn{2}{|c|}{ Adjusted for 1,2} & \multicolumn{2}{|c|}{ Adjusted for $1,2,4-10$} \\
\hline \multirow[t]{9}{*}{$\mathrm{HbA}_{1} \mathrm{c}(\%)$} & Abnormal thirst & 1.45 & $1.34-1.55$ & 1.45 & $1.35-1.56$ & 1.45 & $1.34-1.58$ \\
\hline & Frequent urination & 1.34 & $1.26-1.43$ & 1.34 & $1.26-1.43$ & 1.33 & $1.24-1.43$ \\
\hline & Weight loss & 1.41 & $1.31-1.51$ & 1.41 & $1.32-1.51$ & 1.40 & $1.30-1.51$ \\
\hline & Visual disturbances & 1.07 & $1.00-1.14$ & 1.07 & $1.01-1.15$ & 1.08 & $1.00-1.16$ \\
\hline & Genital itching & 1.16 & $1.09-1.24$ & 1.20 & $1.12-1.28$ & 1.19 & $1.11-1.28$ \\
\hline & Stomatitis & 1.16 & $1.04-1.22$ & 1.16 & $1.04-1.30$ & 1.19 & $1.06-1.34$ \\
\hline & Balanitis (men) & 1.20 & $1.06-1.35$ & 1.20 & $1.07-1.38$ & 1.25 & $1.09-1.44$ \\
\hline & Angina pectoris & 0.92 & $0.83-1.01$ & 0.91 & $0.83-1.01$ & 0.94 & $0.85-1.05$ \\
\hline & & \multicolumn{2}{|c|}{ Unadjusted } & \multicolumn{2}{|c|}{ Adjusted for 1,2} & \multicolumn{2}{|c|}{ Adjusted for $1,3,5-10$} \\
\hline \multirow[t]{5}{*}{$\mathrm{BP}_{\text {systolic }}(\mathrm{mmHg} \times 10)$} & Abnormal thirst & 0.89 & $0.85-0.94$ & 0.89 & 0.84-0.94 & 0.92 & 0.86-0.99 \\
\hline & Frequent urination & 0.92 & $0.87-0.97$ & 0.93 & $0.88-0.98$ & 0.95 & $0.89-1.01$ \\
\hline & Weight loss & 0.91 & $0.86-0.96$ & 0.91 & $0.85-0.96$ & 0.98 & $0.91-1.05$ \\
\hline & Fatigue & 0.94 & $0.89-1.00$ & 0.94 & $0.89-0.99$ & 0.96 & $0.90-1.03$ \\
\hline & & \multicolumn{2}{|c|}{ Unadjusted } & \multicolumn{2}{|c|}{ Adjusted for 1,2} & \multicolumn{2}{|c|}{ Adjusted for $1-4,6-10$} \\
\hline \multirow[t]{5}{*}{ BMI $\left(\mathrm{kg} / \mathrm{m}^{-2} \times 5\right)$} & Weight loss & 0.69 & $0.61-0.78$ & 0.66 & $0.58-0.75$ & 0.62 & $0.54-0.73$ \\
\hline & Visual disturbances & 1.15 & $1.02-1.30$ & 1.08 & $0.96-1.23$ & 1.06 & $0.92-1.23$ \\
\hline & Genital itching & 1.23 & $1.10-1.39$ & 1.10 & $0.97-1.25$ & 1.12 & $0.97-1.30$ \\
\hline & Stomatitis & 1.23 & $1.00-1.50$ & 1.18 & $0.96-1.46$ & 1.15 & $0.91-1.46$ \\
\hline & Angina pectoris & 1.33 & $1.12-1.58$ & 1.52 & $1.26-1.84$ & $1.38^{\mathrm{c}}$ & $1.11-1.72$ \\
\hline
\end{tabular}

Multivariate logistic regression analysis. Odd ratios represent a one-unit change in the dependent variable, i.e. $1 \mathrm{mmoL} / \mathrm{L}$ (FPG), $1 \%$ $\left(\mathrm{HbA}_{1} \mathrm{c}\right), 10 \mathrm{mmHg}\left(\mathrm{BP}_{\text {syst }}\right)$ and $5 \mathrm{~kg} / \mathrm{m}^{-2}(\mathrm{BMI})$.

Adjusted for covariates: 1 age, 2 sex, 3 fasting plasma glucose, 4 systolic blood pressure, 5 body mass index, 6 macrovascular complications, 7 retinopathy, 8 renal involvement, 9 peripheral neuropathy, 10 antihypertensive treatment.

${ }^{\text {a }}$ Fasting plasma glucose

${ }^{\mathrm{b}}$ Recurrent urinary tract infections

c The indication angina pectoris was not adjusted for macrovascular complications. 
ease was not made in models with foot ulcer, gangrene, angina pectoris and intermittent claudication. All symptoms, signs and complications associated with $\mathrm{FPG}, \mathrm{HbA}_{1} \mathrm{c}$, BMI and systolic BP in unadjusted analyses at a $p$ value $<0.10$ are reported in Table 3 . Statistical significance was defined as a $p$ value $<0.05$ (two-sided). All analyses were run on the personal computer statistics package SAS for Windows, version 8.2.

\section{Results}

Baseline characteristics of the patients are presented in Table 1.

Classic diabetic symptoms such as abnormal thirst, frequent urination and weight loss were common (Table 2), and 628 of 1,137 patients $(55.2 \%)$ reported at least two of these symptoms and $24.2 \%$ reported all three.

No symptom, sign or complication other than the 16 predefined ones was reported by more than $3 \%$ of patients. Each of the glycaemic symptoms and signs had been present for less than 3 months before diagnosis for most of the patients whereas cardiovascular complications had often been present for years (Table 2).

After multiple adjustments, six symptoms and signs, i.e. abnormal thirst, frequent urination, weight loss, genital itching, stomatitis and visual disturbances, were associated with both FPG and $\mathrm{HbA}_{1} \mathrm{c}$ (Table 3 ). Furthermore, fatigue and confusion were associated with FPG, and balanitis (in men) with $\mathrm{HbA}_{1} \mathrm{c}$. Only one symptom was associated with systolic BP whereas two were associated with BMI. The nine symptoms and signs associated with the glycaemic level were common and $89 \%$ of the patients presented with one or more of these.

When interpreting the odds ratios in Table 3 , the exponential relationship between the continuous independent variables and the symptom and signs should be noticed. For example, the odds ratio of having the symptom abnormal thirst is 1.37 times as high (1.17 to the power of 2) for someone with an $\mathrm{FPG}=11 \mathrm{mmoL} / \mathrm{L}$ than for someone with an $\mathrm{FPG}=9 \mathrm{mmoL} / \mathrm{L}$ (all other covariates being the same).

In 861 of 1,137 patients $(75.7 \%)$ GPs reported that the diagnostic blood glucose was measured because of the presence of symptoms or acute disease. Other reasons that led the GP to the initial glucose measurement were weight increase $(5.6 \%)$, previous sub-threshold elevation of blood glucose $(4.3 \%)$, or hypertension $(3.2 \%)$. No other reasons were stated for more than $3 \%$ of the study population.

\section{Discussion}

In newly diagnosed type 2 diabetic patients, abnormal thirst, frequent urination, weight loss, genital itching, stomatitis, visual disturbances, fatigue, confusion and balanitis were common, of short pre-diagnostic duration, and associated with glycaemic level.
A Dutch study from 1999 to 2001 [9] found that approximately $75 \%$ of diabetic patients newly diagnosed by GPs had one or more symptoms typical of diabetes, which suggests that the fraction of symptomatic patients has changed little within the last decade despite changes in diagnostic criteria and increasing focus on the disease. In the United Kingdom Prospective Diabetes Study (UKPDS) $31.2 \%$ of the patients were described as asymptomatic [6]; this low percentage most probably reflects the low diagnostic cut-off level $(6.0 \mathrm{mmoL} / \mathrm{L})$ defining diabetes. In a UKPDS sub-sample $(n=438)$, at least one of 40 predefined symptoms and signs (present within the previous week) related either to hyperglycaemia, cardiovascular or respiratory problems, or adverse consequences of drug treatment, was reported after 2 months of glucose-reducing dietary treatment after diagnosis [1]. Next to differences between diagnostic criteria of diabetes, the large variations in type and prevalence of symptoms between the few studies most probably reflect differences in questionnaire methodology and study populations. Another important bias in all studies, including our own, might be that the prevalence of listed items are likely to be overestimated whereas those not listed might have been underestimated.

Duration of symptoms has been reported by two small audits only $[2,7]$. The short duration of symptoms in our study compared with these audits could be a consequence of high motivation among our volunteering doctors, but the relatively high level of diagnostic FPG contradicts this explanation.

Previously, only the prevalence of dry mouth [1], thirst $[1,2]$, stomach pain [1], polyuria [2] and pruritus [2] has been found to be associated with glycaemic level. The few associations found in these studies might be explained by the timing of the interview and limited statistical power, because of the size of the study.

In contrast with the few items found to be associated with systolic BP or with BMI in our multivariate analyses, the UKPDS sub-study found ten symptoms, signs and complications associated with BMI and four with systolic BP [1]. The lack of adjustment for diabetic complications and treatment in the latter study might have biased the findings.

Our results imply that GPs act on symptoms and signs associated with hyperglycaemia and do so reasonable well, because these symptoms and signs were of recent onset. In contrast, very few GPs stated that elevated cardiovascular risk factors and cardiovascular complications led them to test for diabetes. Danish guidelines at the time of the study did not specifically ask GPs to test for diabetes among patients with elevated cardiovascular risk factors and cardiovascular complications. It seems likely, however, that clinical practice might have changed within the last decade, and screening for diabetes among patients with cardiovascular disease, hypertension or dyslipidaemia has recently been suggested in Denmark [10].

In conclusion, our study provides new evidence on several aspects of typical diabetic symptoms and signs. First, nine out of ten type 2 diabetic patients newly diagnosed by the family practice presented with one or more 
hyperglycaemic symptoms or signs. Second, our results provide documentation that nine well-recognised diabetic symptoms are closely associated with hyperglycaemic level whereas few seem to be associated with overweight and elevated BP. Finally, because of the short duration of hyperglycaemic symptoms and signs, our results indicate that compared with raising the awareness of hyperglycaemic symptoms the use of screening models based on cardiovascular risk seems to be a more promising means of early diagnosis of type 2 diabetes.

Acknowledgements We thank the patients and GPs who took part in the study, Lise Bergsoe for secretarial assistance, and Maeve Drewsen for linguistic revision of the paper. Major funding: The Danish Medical Research Council, The Danish Research Foundation for General Practice, The Health Insurance Foundation, The Danish Ministry of Health, Novo Nordisk Farmaka Denmark, and The Pharmacy Foundation.

\section{References}

1. Bulpitt CJ, Palmer AJ, Battersby C, Fletcher AE (1998) Association of symptoms of type-2 diabetic patients with severity of disease, obesity, and blood pressure. Diabetes Care 21:111115

2. Hillson RM, Hockaday TD, Newton DJ, Pim B (1985) Delayed diagnosis of non-insulin-dependent diabetes is associated with greater metabolic and clinical abnormality. Diabet Med 2:383386
3. Ruige JB, de Neeling JN, Kostense PJ, Bouter LM, Heine RJ (1997) Performance of an NIDDM screening questionnaire based on symptoms and risk factors. Diabetes Care 20:491-496

4. Cox DJ, Frederick LG, Pohl S et al (1985) Symptoms and blood glucose levels in diabetics. JAMA 253:1558

5. Hiltunen L, Keinanen-Kiukaanniemi S, Laara E, Kivela SL (1996) Self-perceived health and symptoms of elderly persons with diabetes and impaired glucose tolerance. Age Ageing 25:5966

6. Colagiuri S, Cull CA, Holman RR (2002) Are lower fasting plasma glucose levels at diagnosis of type- 2 diabetes associated with improved outcomes?: U.K. prospective diabetes study 61. Diabetes Care 25:1410-1417

7. Singh BM, Jackson DM, Wills R, Davies J, Wise PH (1992) Delayed diagnosis in non-insulin dependent diabetes mellitus. BMJ 304:1154-1155

8. Olivarius NF, Beck-Nielsen H, Andreasen AH, Horder M, Pedersen PA (2001) Randomised controlled trial of structured personal care of type-2 diabetes mellitus. BMJ 323:970-975

9. Spijkerman A (2003) Thesis: Targeted screening for type-2 diabetes: the Hoorn screening study. Institution for Research in Extramural Medicine, Amsterdam, The Netherlands

10. National Board of Health, Danish Centre for Evaluation and Health Technology Assessment (2003) Type-2 diabetes. Health technology assessment of screening, diagnosis and treatment. Health Technol Assess 1:1-397. Copenhagen, Denmark, National Board of Health, Danish Centre for Evaluation and Health Technology Assessment. http://www.cemtv.dk/publikationer/ docs/Diabetes/type 2 diabetes.pdf 